\title{
Nye bøger
}

Det Kongelige Bibliotek i stobeskeen. Studier og samlinger til bestandens historie indtil ca. 1780

I anledning af indvielsen af Det Kongelige Biblioteks nye tilbygning $\mathrm{i}$ havnefronten, den "Sorte Diamant" udsendes boghistorikeren, fhv. forskningsbibliotekar Harald Ilsøes tobinds værk om bibliotekets historie frem til ca. 1780.

På grundlag af arkivstudier, gennemgang af utrykte kataloger i bibliotekets arkiv og ikke mindst ved at tage utallige bøger og håndskrifter $\mathrm{i}$ øjesyn redegøres der for de oprindelige lag i bestanden tilbage til kongefamiliens besiddelser i 1500-tallet. Til den kongelige slægtsarv og til sit eget bibliotek føjede Frederik 3 erhvervelser af fem betydelige privatbiblioteker, og under de følgende konger blev biblioteket fortsat udbygget ved køb og krigserobringer af hele eller dele af righoldige privatbiblioteker. Harald Ilsøe har eftersporet bøgerne i bibliotekets nuværende bestand, og har fulgt deres historie tilbage til de tidligere ejere. De enkelte samlingserhvervelser belyses ved hjælp af gamle kataloger, ved fremdragelse af eksemplarer og ved undersøgelse af ejermærker og bogbind. Hermed kastes også nyt lys over en række af de håndskrifter, der kam til at udgøre fundamentet for den nuværende "Gamle kongelig Samling”. Flere af disse håndskrifters proveniens har tidligere ligget hen $\mathrm{i}$ det dunkle.
Det Kongelige Bibliotek $i$ støbeskeen udkommer som bind $21 \mathrm{i}$ skriftserien Danish Humanist Texts and Studies, der redigeres af Erland Kolding Nielsen. 2 bind, 720 s. Rigt illustreret, indb. Kr. 500,-

\section{J.P.E. Hartmann og hans kreds. En komponistfamilies breve 1780-1900} Udgivet med indledning og noter af Inger Sørensen.

J.P.E. Hartmann (1805-1900)

er et den danske musikhistories allerstørste navne. I løbet af sit lange liv korresponderede han med mange af guldalderens forfattere og kunstnere såsom H.C. Andersen, Oehlenschläger, Heiberg, Hostrup, Ploug og August Bournonville. Han stod også i forbindelse med udenlandske komponister som Liszt, Mendelssohn, Heinrich Marscher, Louis Spohr og Grieg. Sønnen Emil Hartmann, der også var komponist, er repræsenteret ved en lang række breve, der både kaster lys over hans egen kamp for anerkendelse og over tidens københavnske musikliv. Brevsamlingen indeholder breve til og fra flere hundrede af 1800-tallets per-sonligheder og er af almen kulturel interesse.

\section{J.P.E. Hartmann og hans kreds} udkommer som bind $17 \mathrm{i}$ skriftserien Danish Humanist Texts and Studies, der redigeres af Erland Kolding Nielsen. 3 bind, 1800 s. Illustreret, indb. Kr. 650,- 


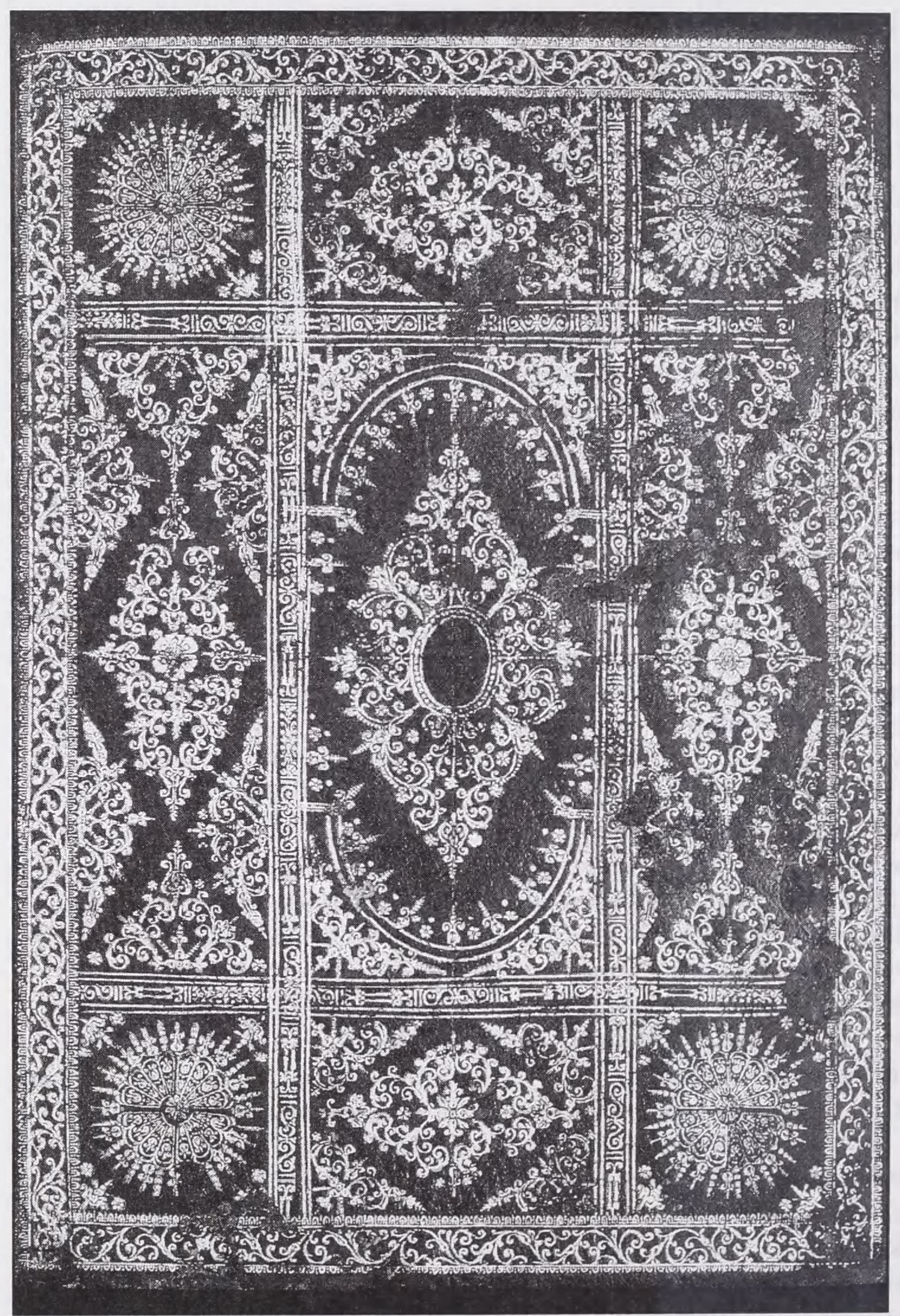

Bindet om eksemplaret af den af hertug August af Braunschweig-Lüneburg udgivne Evangelische Kirche-Harmonie, Wolfenbüttel 1645, som hertugen skankede Frederik 3. 
Runemester ved arbejdet. Illustration fra artiklen $i$ Fund og Forskning om

Odinskjalden.

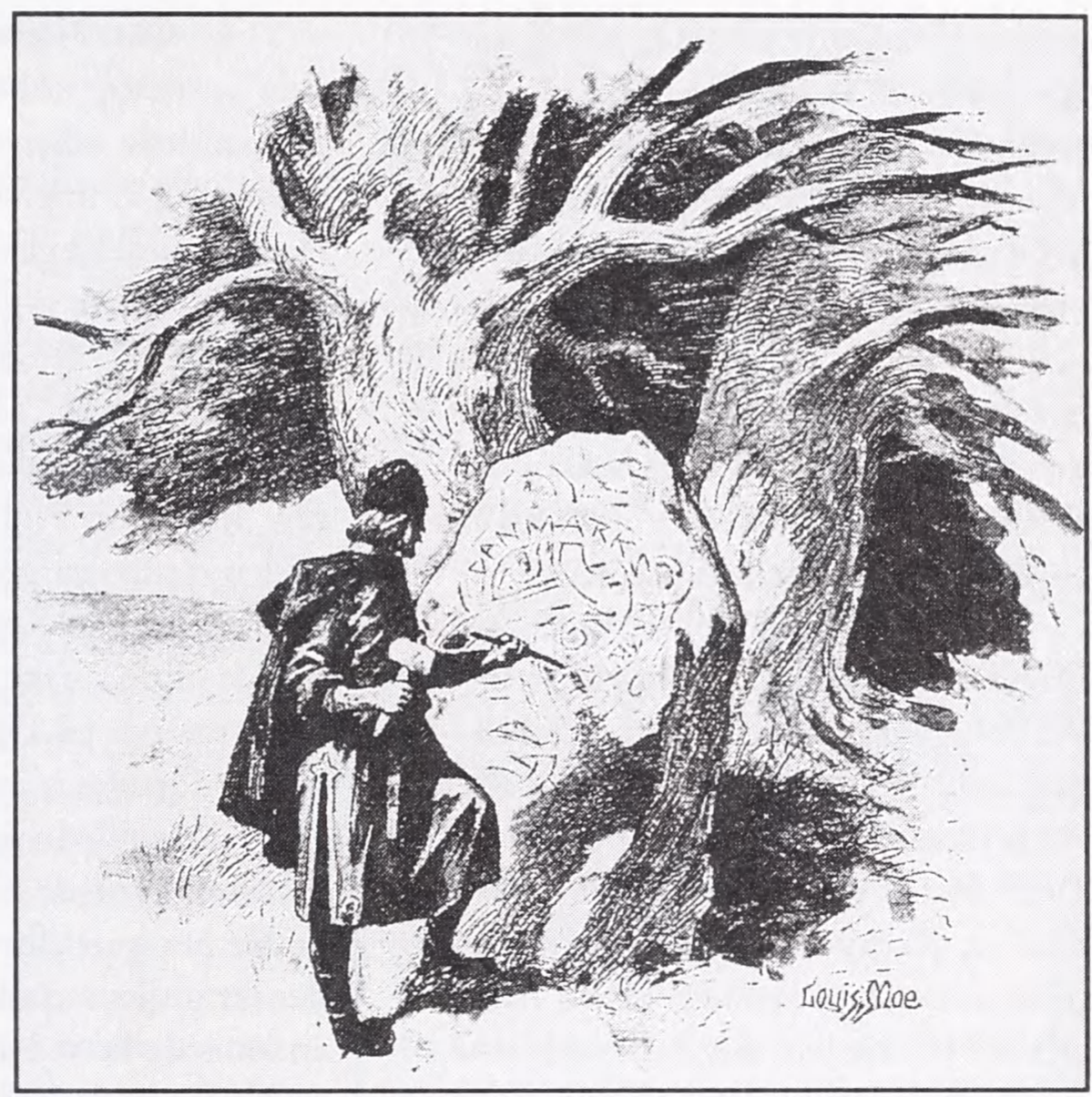

Fund og Forskning, bind 38

Indholdet spænder kronologisk fra tidlig middelalder til 1960'erne.

Emnemæssigt er der som vanligt for årbogen originalt stof over et meget bredt kulturhistorisk felt i relation til Det Kongelige Biblioteks samlinger og forskning.

Professor Louis Christensen, Seattle Universitet, lægger for med et originalt forsøg på at betragte den tidlige skjald, Odinskjalden, hos historieskriveren Saxo som musiker. Skjalden anskues som en sanger, der genskaber sin sociale eller nationale gruppes mundtlige overlevering ved hjælp af et poetisk system. Derpå følger ekstern lektor, dr. phil Jens Chr. V. Johansens udgivelse af biskop i Ålborg, Jens
Bircherods dagbog for året 1658 med en undersøgelse af dagbogens kilder.

Bircherod kan nemlig ikke selv have været noget særligt godt vidne for 1658 - det år, hvor han selv blev født! Konklusionen er, at der ved dagbogens senere konstruktion også må være anvendt kilder, som vi ikke kender i dag.

Fhv. direktør Arthur Arnheim og seniorforsker Ulf Haxen redegør for rabbi Moses Hagiz og det hebraiske bogtrykkeri i Aktona i begyndelsen af 1700-tallet. Inden for et kort åremål (1726-33) blev der trykt et meget stort antal hebræiske bøger skrevet af jøder og bestemt for den jødiske offentlighed i Danmark. Ph.-D Philippe Provencal, Naturhistorisk Museum i Århus, tager i sit bidrag naturforskeren Peter Forskåls 
indsats for arabisk leksikografi op til undersøgelse. Forskål (1732-63) var med på den bekendte såkaldte "arabiske rejse”, en dansk ekspedition i 1760 'erne, hvor der blev indsamlet videnskabeligt materiale, bl.a. Forskåls indsamlinger og beskrivelser af planter og dyr. Provencal når til det resultat, at Forskål har ydet et meget betydeligt og varigt bidrag til såvel leksikografien som til den arabiske civilisations videnskabshisstorie.

Forskningsbibliotekar Thorkild Davidsen publicerer uddrag af Jens Warmings dagbøger hidtil uudgivne dagbøger. Warming var professor i statistik ved Københavns Universitet 1919-39. Af dagbøgerne fremgår det bl.a., at Warmings store ønske var at blive professor i økonomi, men hans arbejde på det felt blev ikke værdsat i samtiden. Frustrationen over dette og egen overbevisning om værdien af arbejdet, dokumenteres til fulde i dagbøgerne. Først en sen eftertid har anerkendt hans originale bidrag til økonomisk teori. Forfatteren John Fellow har i årbogens længste bidrag og på baggrund af hidtil ubenyttet kildestof minutiøst afdækket de indre brydninger i Dansk Tonekunstnerforening i begyndelsen af dette århundrede med nogle af tidens kendte musikere, komponister og kritikere som aktører. Bl. a. Carl Nielsen. Foreningen blev i 1920 og 30'erne en betydningsfuld organisation i det danske musikmiljø, men først efter at have gennemgået nærmest traumatiske børnesygdomme, som der her redegøres for for første gang og har affødt artiklens titel: "Da danske musikere var blevne til børn igen".
Carl Nielsen opera "Maskerade" er netop udkommet som en del af den samlede udgave af komponistens musik. En af udgiverne, redaktør Peter Hauge, undersøger i artiklen "Pigen med den skæve ryg" de forkortelser, som Carl Nielsen i løbet af den senere del af sit liv foretog af "Maskerade" og hvilke problemer, det stiller en udgiver overfor. Fhv. lektor Lis Pihl tegner på grundlag af den omfangsrige Hackett/Toksvig samling på Det Kongelige Bibliotek et billede af den irske forfatter Frances Hacketts syn på Danmark. Han havde særlige forudsætninger for at udvikle et Danmarksbillede, idet han giftede sig dansk og flyttede til Danmark i 1937 og boede her kun afbrudt af anden verdenskrig til sin død i 1962. På den anden side lærte han aldrig sproget, det forhindrede en kulturel integration, og han forblev en irer, der så Danmark gennem meget "irsk-farvede" briller.

Årgangen slutter med et publiceringen af hidtil ukendte personalhistoriske oplysninger fra Karel van Manders familiebibel ved fhv. seniorforsker Harald Ilsøe, og professor ved Hamborgs Universitet, Klaus Alpers' opposition til Erik Petersens disputats Intellectum Librare.

\section{Årgangen er redigeret af}

bibliotekets forskningschef, $\mathrm{dr}$. phil. John T. Lauridsen og førstebibliotekar, mag. art. Stig T. Rasmussen.

Prisen på bind 38 (371 s., ill.) er fortsat 250 ,- kr. i abonnement plus forsendelsesomkostninger og 350,- kr. i løssalg, begge priser incl. moms. 
John T. Lauridsen: Krig, kobmand og kongemagt - og andre 1600-tals studier

Bogen er i fire dele med 20 kapitler. De fleste artikler har tidligere været offentliggjort, men er ført ajour. Nogle artikler har karakter af essays, andre er dyberegående studier. Det generelle tema er det øverste danske borgerskab og ikke mindst dets forhold til statsmagten i 1600-tallet, men der tages også stilling til den generelle sociale og retlige udvikling i perioden og dykkes ned i et par lokalsamfund i bogens første del.

I anden og tredie del sættes med en række delstudier fokus på den danske statsmagts største forretningsforbindelse $\mathrm{i}$ århundredet, Bern-Marselis-Klingenberg-gruppen. Først undersøges $i$ anden del sider af slægtsforholdene og forretningsaktiviteten, $i$ tredie del tages med udgangspunkt $i$ en enkelt representant for storkøbmændene, Poul Klingenberg, fat på belysning af storkøbmændenes vilkår under den tidlige enevælde.

Bogens sidste del bringer to historigrafiske artikler med vægten på historikeren Johan Jørgensens forfatterskab og bidrag til udforskning af det danske borgerskabs historie.

John T. Lauridsen: Krig, kabmand og kongemagt - og andre 1600-tals studier udkommer som bind $17 \mathrm{i}$ skriftserien Danish Humanist Texts and Studies, der redigeres af Erland Kolding Nielsen. 1999. 331 s. Kr. 275,-

\section{Krig, kobmand og kongemagt}

knytter sig til forfatterens tidligere udgivne: Marselis-konsortiet. En studie over forholdet mellemhandelskapital og kongemagt i 1500-tallets Danmark, 1987.

\section{Danske Provinstryk 1482-1830}

Det fjerde bind af Danske Provinstryk omfatter 807 bøger, pjecer og aviser fra fire sønderjyske - eller med historisk sprogbrug nordslesvigske - byer ud af de 24 danske byer, som hele værket omfatter.

Disse bogtrykkere rækker kun tilbage til første halvdel af 1700-tallet. Til gengæld går de alle ud over grænsen 1830. Aaberaa melder sig overhovedet først 1826 medd Christian August Rathjes 14 tryk og Sønderborg 1815 med den hannoveranske skuespiller Carl Wiswes lille firma med 26 tyske og 14 danske skrifter: taler og sange, bøger for skolebørn, auktionskataloger og andet fra dagligdagen.

\section{Langt vægtigere er de 97 tryk}

fra Tønder, især dem fra Vajsenhusets trykkeri med Hermann Hinrich Rottmer og dets senere ejere, Claus Kiessbuy, Lorenz Petersen og Johann Anthon Reinhold 1735-70. Her hæfter man sig selvfølgelig ved tre dyrebare Brorsonsalmehæfter og ved hans foresatte provst Schraders skrifter på både tysk og dansk, og man kan undre sig over, at der trykkes en komplet tysk Bibel. Men her som i hele bindet muliggør netop DPt's lokalhistoriske anlæg at studere forholdet mellem landsdelens to sprog, ligesom de lokale avisers vigtige historie belyses. Efter mere end 40 års pause gives der i 1813 trykkeribevilling til den foretagsomme enke efter rektor J.L. Forchhammer, Margrethe Elisabeth Forchhammer. Hun oplevede i sit 92. år at få frataget privilegiet, bl.a. på grund af de politiske forhold i grænselandet. 
Helt dominerende i bindet er dog Haderslev, hvor Hinrich Luckanders trykkeri fra 1759 overtages af Jens Jensen Seneberg i 1793 og ved bibliografiens tidsgrænse af dennes søn. Hver af de to ejere leverer ca. 250 tryk, men dertil kommer en mængde tryk uden navn og år, så tallet kommer op på 656. Mere end en tredjedel af disse findes ikke i den grundlæhggende bibliografi Bibliotheca Danica. Blandt emnerne kan som sædvanlig nævnes teologi og ikke mindst elementærbøger heri, personalhistorie ofte i form af festsange og ligprædikener samt småskrifter om alskens lokale forhold. Men noget helt specielt er Haderslev-trykkeriets meget store produktion af kisteblade, skillingsviser og folkebøger, som kun findes i yderst beskedent omfang i de øvrige provinsbogtrykkerier. DPt IV har som de andre bind lokal-, erhvervs- og personalhistorisk interesse ud over den boghistoriske, ligesom nutidens voksende interesse for læsevaner kan finde støtte her.

\section{Danske Provinstryk 1482-}

1830. En bibliografi udarbejdet af Grethe Larsen under redaktion af Erik Dal. IV: Sønderjylland. Det danske Sprog- og Litteraturselskab og Det Kongelige Bibliotek. I kommission hos C.A. Reitzels Forlag. 1998. XXXII + 146 s. Indb. kr. 350,- Bd. I-VI i abonnement kr. 312,50 pr. bind.

Alle Det Kongelige Biblioteks publikationer kan ses på adressen: www.kb.dk/ kultur/salg/ 